\title{
VIVÊNCIAS E NARRATIVAS DE TRABALHADORAS DOMÉSTICAS DIARISTAS
}

EXPERIENCE AND NARRATIVES OF DOMESTIC DAY LABORERS

\author{
Ítala Lopes Cardoso* \\ Sílvia Maria Ferreira Guimarães**
}

\begin{abstract}
Resumo
No contexto atual do mercado de trabalho, persiste a informalidade, condição em que se encontram as diaristas, trabalhadoras domésticas sem vínculo formal, foco deste estudo, que tem como objetivo a análise das representações e percepções sobre a informalidade do contrato de trabalho e dos riscos à saúde de trabalhadoras domésticas diaristas. Este trabalho está baseado nas histórias de vida de quatro trabalhadoras, residentes nas cidades do entorno do Distrito Federal, em municípios localizados no estado de Goiás, Brasil, que atuam como diaristas, realizando trabalhos domésticos em Brasília, Distrito Federal. As narrativas dessas mulheres apresentaram temas relativos às "trajetórias ocupacionais", "práticas cotidianas na faxina” e "percepções de saúde". Essas histórias de vida revelam contextos de exclusão social, marcados pela violência de gênero, racismo e violência nas relações trabalhistas, ao mesmo tempo em que apresentam estratégias de subversão dessas práticas por essas mulheres.
\end{abstract}

Palavras-chave: Trabalhadoras domésticas diaristas. Trabalho feminino. Relações trabalhistas. Saúde do trabalhador.

\begin{abstract}
In the current Job market context persist the informality, that the day laborers have reached. They arefemale workers who work in informality in paid domestic work, targeted of this research. The objective of this research is to analyse the representations and perceptions about the informality of the work contract and the health risks of domestic day laborers. This research is based on life story of four women workers, residents of the cities surrounding the Federal District, in the state of Goiás, Brazil, acting as day laborers, doing domestic work in Brasília, Federal District. The narratives of these women have presented themes relating to "occupational trajectories", "daily housecleaning practice" and "perceptions of health". Their life stories reveal settings of social exclusion, marked by gender violence, racism and violence in labour relationship at the same time as presenting strategies of subversion of such practices by these women.
\end{abstract}

Keywords: Housekeeping. Working women. Labour relations. Worker's health.

\section{Introdução}

Exercido por mulheres negras, pobres e com baixa escolaridade, em sua maioria, o trabalho doméstico é marcado pela precariedade das relações de trabalho e, apesar de sua importância ao ter como protagonistas mulheres que descolonizam relações de trabalho e

\footnotetext{
Mestre em Ciências e Tecnologias em Saúde pela Universidade de Brasília. E-mail: italalopescardoso@gmail.com

** Doutora em Antropologia pela Universidade de Brasília, é professora do Programa de Pós-Graduação em Ciências e Tecnologias em Saúde, do Programa de Pós-Graduação em Antropologia Social e do Mestrado em Sustentabilidade junto a Povos e Terras Tradicionais, da Universidade de Brasília. E-mail: guimaraes.silvia@gmail.com
} 
apresentam organizações e agências que mobilizam a dinâmica capitalista no enfrentamento da desigualdade (BERNARDINO-COSTA, 2015), é desvalorizado por compreender um processo de qualificação que ocorre fora das instituições formais de ensino e se relaciona com corpos de sujeitos marcados pelo preconceito, racismo e processos de colonização. Essas mulheres recebem baixa remuneração e vivenciam situações de desigualdade de gênero, raça e classe (FREITAS, 2010; COUTINHO et al., 2013).

No Brasil, $92 \%$ dos empregos domésticos são ocupados por mulheres, e esta é a ocupação de 5,9 milhões de brasileiras, o equivalente a 14\% do total das vagas ocupadas por este segmento populacional (PINHEIRO et. al., 2016). No âmbito das ocupações, as mulheres encontram-se em situações precárias. Isso tem sido explicado pela sua exclusão do mundo do mercado de trabalho por razões de violências estruturais que as subordinam ao patriarcado, em que a dicotomia entre o papel feminino, assentado na reprodução biológica, com ênfase na maternidade e na realização de afazeres domésticos, e o papel masculino, no exercício do poder econômico na esfera pública, foi traçada ao longo de todo o processo histórico no Brasil (MELO; CONSIDERA; DI SABBATO, 2007). Soma-se a essa desigualdade de gênero, questões raciais e de classe social, ou seja, no caso da mulher negra, parda ou indígena, e pobre, ampliam-se os contextos de violência e subordinação (HOOKS, 1995).

De acordo com Bernardino-Costa (2015), no processo de constituição do "sistemamundo moderno/colonial", as categorias de raça e trabalho, aqui ampliando para a de gênero, foram relacionadas, configurando uma divisão racial do trabalho desde os tempos coloniais até o presente. Esse processo histórico instaurado com o colonialismo configurou uma situação em que o trabalho assalariado era desempenhado pelos europeus e seus descendentes, enquanto o colonizado não recebia salário ou estava incluído na categoria de escravo.

A condição de escravo vem sofrendo transformações ao longo da colonialidade que ainda se impõe em países como o Brasil. Tal condição, hoje, recebe denominações como trabalho forçado, servidão por dívida e tráfico humano. De acordo com Leão (2016), no capitalismo contemporâneo emergem novas e variadas formas de trabalho escravo, fato comum em todas é ser um fenômeno vinculado a modelos de desenvolvimento econômico e padrões de acumulação capitalista. Além disso, na esteira da discussão desse autor, esses formatos de trabalho escravo referem-se a situações nas quais o "trabalhador tem um conjunto de direitos negligenciados, é exposto a condições de trabalho perigosas e tratado como propriedade ou levado a trabalhar sem o consentimento ou por coerção" (LEÃO, 2016, p. 3928).

Macedo (2015) discute como no período pós-abolição, o trabalho doméstico passou a ser uma atividade feminina no já constituído espaço da vida doméstica colonizadora e ainda era compreendido como uma "ajuda" em troca de casa e comida. Mesmo com o processo de industrialização, urbanização, presença de sindicatos, uma gama de trabalhadoras domésticas passa ao largo dessas interações e discussões e ainda permanece em seus trabalhos com essa ideia de "ajuda”. No entanto, é preciso ressaltar que o sindicato das empregadas domésticas 
se estabeleceu, contrapondo-se a esse contexto de exploração. Tais formas de organização em sindicatos ou associações são analisadas como narrativas e práticas decoloniais desencadeadas por essas mulheres, na pesquisa de Bernardino-Costa (2015). Contudo, observa-se que, no caso do trabalho doméstico, transitar entre estar legalizada, na informalidade ou no trabalho escravo, é uma constante.

Ao longo desses processos históricos, no Brasil, o trabalho doméstico foi sendo concebido como um trabalho desqualificado, que qualquer pessoa pode realizar, tornando-se estigmatizado por envolver sujeira, corpos e intimidade e por ser ocupado por pessoas definidas como de status mais baixo. Há quem defenda, ainda hoje, que limpar, cozinhar, lavar, cuidar das crianças e dos doentes são habilidades naturais das mulheres e, devido a isto, o trabalho doméstico constitui o tipo mais comum de trabalho não pago (MELO; CONSIDERA; DI SABBATO, 2007; BORIS, 2014)). Isso se configura como violência de gênero no âmbito das ocupações que, ainda hoje, no Brasil, escraviza muitas mulheres, jovens e crianças.

O trabalho informal é caracterizado pelas precárias condições de trabalho, pela falta de registros oficiais na carteira de trabalho e, assim sendo, os trabalhadores informais são privados dos benefícios de seguridade social e não se encontram cobertos por medidas de proteção à saúde (IRIART, 2008; COUTINHO et al., 2013). Enquanto o trabalho das empregadas domésticas encontra-se regulamentado em diversos dispositivos legais, o trabalho das diaristas permanece sem respaldo legal (PRISCO; CARVALHO; GOMES, 2013). A média de estudo delas é de seis anos e meio, o salário é de aproximadamente $\mathrm{R} \$ 700$, e, até 2014 , mais de $70 \%$ não tinham carteira assinada (PINHEIRO, 2016).

As trabalhadoras em serviços domésticos são as que apresentam maiores sintomas de depressão e ansiedade, como tristeza e desânimo, dificuldade de concentração, palpitações e agressividade, além da alta incidência de acidentes ocupacionais não fatais nessa ocupação, estimada em $7,3 \%$, enquanto a incidência entre mulheres que exercem outras ocupações está em 4,5\% (IRIART, 2008). Esse quadro torna-se ainda mais complexo, pois existe uma série de outros fatores, para além do trabalho doméstico, que influenciam negativamente a saúde destas trabalhadoras, como a falta de lazer, a violência, o racismo, a dificuldade de acesso aos serviços de saúde e o desamparo por parte do Estado.

Embora existam estudos quantitativos sobre a organização social do trabalho doméstico, estudos qualitativos que buscam qualificar e identificar as percepções destas trabalhadoras sobre seu próprio universo laboral, sua história de vida, seus problemas de saúde, suas demandas e aspirações, são escassos (MORI et al., 2011). Estudos sobre como pensam, percebem e se posicionam as trabalhadoras em relação a este tipo de inserção no mercado de trabalho, e sobre como esse tipo de vinculação afeta a sua saúde e segurança, impondo-lhes riscos, são fundamentais para o desenvolvimento de estratégias inovadoras, que contemplem políticas de promoção da saúde e de prevenção e controle dos riscos ocupacionais (IRIART, 2008). Além disso, pesquisadores têm chamado atenção para a dimensão social e cultural do risco, 
apontando a importância de se compreender o ponto de vista de trabalhadores expostos a riscos ocupacionais, para que esse conhecimento possa subsidiar processos decisórios e de regulação desses riscos (IRIART, 2008; AMORIM, 2008; YOSHIKAI, 2009).

Portanto, investigar o trabalho doméstico significa apreender o universo de milhões de trabalhadoras brasileiras que ainda se encontram à margem da produção acadêmica e, no caso da saúde pública, permitir que haja uma reflexão acerca da representação social do trabalho doméstico e da percepção sobre os riscos à saúde destas trabalhadoras, verificando dimensões de segregação e marginalização marcadas pela pobreza, raça, etnia e gênero.

De modo a preencher essa lacuna do conhecimento, realizou-se este estudo, que tem como objetivo principal: analisar as representações e percepções sobre a informalidade do contrato de trabalho e dos riscos à saúde de trabalhadoras domésticas diaristas; e como objetivos específicos: conhecer e descrever a história de vida das diaristas, contextualizar as condições de vida, trabalho e saúde em que estão inseridas as trabalhadoras domésticas na sociedade, identificar as práticas/estratégias de cuidado de trabalhadoras domésticas no enfrentamento de seus problemas cotidianos relacionados à vida e à saúde.

\section{Localizando e trilhando o campo}

Para compreender a relação entre o trabalho doméstico, as formas de cuidado e as percepções de saúde que cercam a vida das diaristas, optou-se por realizar um estudo que permita a produção de uma teoria do social a partir do encontro entre pesquisadoras e sujeitos. Peirano (1991) afirma que o encontro etnográfico permite a construção de uma teoria etnográfica que não se refere somente ao grupo ou pessoas, nem somente ao pesquisador, mas resulta da interação entre esses dois sujeitos. Segundo Minayo (2010) esse tipo de abordagem resultada em um trabalho coletivo proveniente da interação entre sujeitos.

Foram feitos estudos biográficos, que segundo Sánchez (1995) é o mesmo que buscar narrativas sobre a história de vida. Através da narrativa da história de vida de uma pessoa é possível entender o processo pelo qual um sujeito traça sua trajetória, como ele o faz relacionado a sua sociocosmologia e como os indivíduos se definem ou se reconhecem em relação ao grupo social ao qual pertencem (MURILLO, 2013). A partir das narrativas biográficas, não se conhece apenas um itinerário ou uma trajetória, mas também relações e interações entre pessoas, instituições e políticas que são muito reveladoras do contexto contemporâneo, o que permite o trânsito entre macro e micro, na interface das políticas que marcam corpos e pessoas em seu cotidiano (MANICA, 2010). É importante ressaltar que o relato biográfico é um texto e não uma vida e, portanto, uma história de vida não pode ser escrita em toda sua totalidade em poucos capítulos (MURILLO, 2013).

Pierre Bourdieu (1996) defende que as trajetórias de vida são estabelecidas pela série de acontecimentos experimentados pelo indivíduo dentro de um campo no qual ele age, no qual ele 
exerce e sofre influência. No caso do presente estudo, o campo é representado pelo trabalho em serviços domésticos, onde não será apresentada a vida das diaristas em sua totalidade, mas os acontecimentos relatados por elas que pretendem explicar e complementar as suas experiências no serviço doméstico.

Segundo Sánchez (1995), neste tipo de estudo, deve-se evitar as entrevistas estruturadas, pois qualquer pergunta pode prejudicar a obtenção de uma história de vida de acordo com a própria percepção do entrevistado, sendo aconselhável dar aos entrevistados liberdade suficiente para narrar suas histórias sem imposições. Diante disso, nesta pesquisa, foram estabelecidos diálogos que se basearam nas histórias de vida e nas estratégias de enfrentamento frente aos problemas encontrados em seus cotidianos, a fim de obter, através da narrativa das diaristas, seus pontos de vistas, percepções e significados que orientam e influenciam suas escolhas e relações de trabalho.

As participantes deste estudo foram identificadas por meio da técnica do snowball, que é uma técnica de identificação de participantes a partir de uma rede de conhecidos próximos. Elas foram selecionadas com base nos seguintes critérios: ser mulher; exercer o trabalho doméstico remunerado na categoria profissional de diarista, ou seja, sem vínculo empregatício; ser moradora da região do entorno do Distrito Federal, em municípios do estado de Goiás, com o intuito de analisar como ocorrem os deslocamentos dessas trabalhadoras na lida diária entre centros urbanos.

Nas entrevistas foram abordados temas sobre a trajetória de vida das diaristas, tais como sua origem e criação, família, educação, casamento e filhos, sobre suas experiências de trabalho, de como iniciou na profissão, seu relacionamento com os patrões, trajeto para o trabalho, as atividades que executa durante a faxina, a jornada de trabalho, remuneração, carteira de trabalho, Previdência Social, sobrecarga e acidentes no trabalho; e sobre suas percepções de saúde, estratégias de cuidado, meios e lugares mais acessados por elas em caso de doença e o cuidado com os filhos. Também foram abordados temas como discriminação racial, assédio sexual, violência doméstica, auxílios e benefícios proporcionados pelo Estado.

As entrevistas ocorreram durante os meses de agosto de 2016 a janeiro de 2017, foram transcritas, sendo modificados apenas os nomes das diaristas, de seus familiares e de seus empregadores, quando estes eram relatados, mantendo a postura ética e confidencial acordada com as informantes.

\section{Localizando as trabalhadoras em questão}

Este trabalho contempla quatro mulheres que exercem ou exerciam o trabalho doméstico remunerado durante a maior parte de suas vidas na categoria profissional de diarista. Elas residem em cidades localizadas no entorno do Distrito Federal, municípios do estado de Goiás, 
e precisam percorrer, diariamente, grandes distâncias para chegar até seus locais de trabalho, que se encontram nos bairros de classe média e alta do Distrito Federal.

A região do entorno do Distrito Federal é uma microrregião do estado brasileiro de Goiás, que compreende vinte municípios (Abadiânia, Água Fria de Goiás, Águas Lindas de Goiás, Alexânia, Cabeceiras, Cidade Ocidental, Cocalzinho de Goiás, Corumbá de Goiás, Cristalina, Formosa, Luziânia, Mimoso de Goiás, Novo Gama, Padre Bernardo, Pirenópolis, Planaltina, Santo Antônio do Descoberto, Valparaíso de Goiás, Vila Boa e Vila Propício), tendo uma população de 1.015.010 habitantes, dos quais 50,12\% são mulheres (IFG, 2012; IBGE, 2010). Essa região é estigmatizada por ser uma área violenta, sem estrutura e políticas públicas adequadas. Há um trânsito intenso de trabalhadores desses municípios para Brasília, além de pessoas em busca de serviços de saúde (QUEIROZ, 2006).

Dos vinte municípios que integram a região do entorno, quatro abrigam as diaristas participantes desta pesquisa. Ivone reside no município de Luziânia, situada a uma distância de $58 \mathrm{~km}$ de Brasília. É o município mais populoso da região do entorno de Brasília, com uma população estimada de 196.864 habitantes (IBGE, 2016). Ana é moradora do Pedregal, bairro do município de Novo Gama, localizado a $54 \mathrm{~km}$ da capital federal. Possui uma população estimada de 108.410 habitantes (IBGE, 2017b). Neuza reside no município de Águas Lindas de Goiás, localizado a $70 \mathrm{~km}$ de Brasília, com uma população estimada de 191.499 habitantes (IBGE, 2016). Bete mora em Valparaíso de Goiás, situada a 35 km de distância de Brasília e com uma população estimada de 156.419 habitantes (IBGE, 2016).

O perfil sociodemográfico das trabalhadoras participantes deste estudo é apresentado no quadro 1, e vai ao encontro do que é referido na literatura sobre o trabalho informal, que se caracteriza pela baixa escolaridade, predominância de pessoa da cor negra ou parda, história de migração do interior do estado para a capital, inseridas no mundo do trabalho antes da maioridade e todas com vínculo informal (IRIART, 2008; BRITES 2013; COUTINHO et al., 2013).

Quadro 1 - Perfil das trabalhadoras domésticas entrevistadas

\begin{tabular}{lrrrrr}
\hline Nome & Ivone & Ana & Neuza & Bete \\
\hline Idade & 50 & 54 & 42 & 40 \\
& Escolaridade & $\begin{array}{r}\text { Ensino fundamental } \\
\text { incompleto }\end{array}$ & $\begin{array}{r}\text { Ensino fundamental } \\
\text { incompleto }\end{array}$ & $\begin{array}{r}\text { Ensino fundamental } \\
\text { incompleto }\end{array}$ & $\begin{array}{r}\text { Ensino médio } \\
\text { completo }\end{array}$ \\
Cor/Etnia & Branca & Parda & Negra & Parda \\
$\begin{array}{l}\text { Cidade/Estado de } \\
\text { Origem }\end{array}$ & Salgadinho -Paraíba & Araioses - Maranhão & São Francisco- Piaúi & $\begin{array}{r}\text { Planaltina - } \\
\text { Goiás }\end{array}$ \\
\hline
\end{tabular}




\begin{tabular}{|c|c|c|c|c|}
\hline $\begin{array}{l}\text { Idade que } \\
\text { Começou a } \\
\text { Trabalhar }\end{array}$ & 11 anos & 14 anos & 7 anos & 14 anos \\
\hline $\begin{array}{l}\text { Tipo de Vínculo } \\
\text { Empregatício }\end{array}$ & Diarista & Diarista/ Mensalista & Diarista & Diarista \\
\hline Situação Conjugal & Divorciada & $\begin{array}{r}\text { Casada sem registro } \\
\text { civil }\end{array}$ & $\begin{array}{r}\text { Casada com registro } \\
\text { civil }\end{array}$ & $\begin{array}{r}\text { Casada sem re- } \\
\text { gistro civil }\end{array}$ \\
\hline Filhos & 1 & 4 & 3 & 1 \\
\hline $\begin{array}{l}\text { Local Onde } \\
\text { Reside }\end{array}$ & Luziânia & Novo Gama & $\begin{array}{r}\text { Águas Lindas de } \\
\text { Goiás }\end{array}$ & $\begin{array}{r}\text { Valparaíso de } \\
\text { Goiás }\end{array}$ \\
\hline $\begin{array}{l}\text { Característica da } \\
\text { Moradia }\end{array}$ & Casa própria & Casa alugada & Casa própria & Casa própria \\
\hline
\end{tabular}

Fonte: Produzido pela autora.

\section{Desvendando narrativas, contextos e sujeitos}

\section{Trajetórias Ocupacionais}

Essas mulheres vieram para a região do DF ainda crianças ou adolescentes, suas trajetórias são marcadas pela relação de compadrio do meio rural onde os filhos circulam em momentos de necessidade, mas, quando estão em Brasília, adentram em outra lógica, a da exploração do trabalho infantil, ranços de uma colonização dos corpos de meninas pardas e negras que se replica no Brasil ao longo do tempo e do espaço. Assim, dentre as quatro mulheres que conversamos, três são imigrantes da região nordeste do país, chegaram à Brasília ainda jovens em busca de melhores condições de trabalho e de vida. Este fato foi narrado por elas como tendo ingressado no trabalho doméstico quando ainda eram crianças sob as ordens dos próprios pais, que viam o emprego de seus filhos como alternativa para a subsistência da família. Todas as entrevistadas começaram a trabalhar entre 7 e 14 anos de idade em "casas de família", varrendo chão, lavando a louça, cozinhando, lavando e passando roupas e "olhando crianças".

"(Comecei a trabalhar) Quando nasci. (Rindo) Brincadeira! Com 11 anos de idade eu já vim pra cá trabalhar, né? Eu vim com meu pai pra cá (Brasília). A diferença é que eu trabalhava de graça, só por uma comida e uma roupinha, com 11 anos, né?! Aí com 12 anos eu fui embora pra lá de novo (Para sua cidade natal, Salgadinho/PB). Aí comecei lá, não tinha emprego, aí eu botava água na rua pros outros, pra aquelas casas, botava água na rua. Aí depois eu arranjei emprego assim por perto, em Patos (Patos/PB), Campina (Campina Grande/PB). Larguei a cidade e fui trabalhar lá, em casa de família mesmo. É fazendo faxina. Limpar a casa, passar roupa, fazer comida."(Ivone) 
"Eu sou do Maranhão. Aí eu saí do Maranhão com 14 anos. Eu sou de Araioses. Aí eu vim com 14 anos. Fiquei aqui (Brasília). Não conhecia ninguém. Aí fiquei na casa de uma amiga da gente que é comadre do meu pai. Aí de lá pra cá (desde de minha vinda para Brasília), eu fiquei com ela e fui mudando. (No primeiro emprego) Eu morava no serviço, direto. Passei 12 anos morando no serviço. Foi assim, eu ia pro Rio de Janeiro, mas aí não fui. Eu não fui pro Rio de Janeiro porque eu chorei com medo de deixar meu pai e minha mãe. Aí veio uma vizinha da gente, que mora de frente com a minha mãe, lá na casa de meu pai, lá no Maranhão. Bem pertinho mesmo. Então ela disse: "Ê moço, tu deixa a Ana ir pra Ceilândia (Bairro do DF) pra cuidar de dois meninos?” Aí, eu vim pra cá em 80. Aí eu vim. Quando eu chego na Ceilândia, não era pra cuidar de dois meninos, era pra cuidar da casa, com tudo, e ainda lavar roupa na mão. Eles não pagavam muito não, sabe por quê? Porque eu era de menor ainda. Ela descontou, porque quando eu cheguei aqui, eles compraram as roupas pra mim. Eu não trouxe nada. Eles compraram roupa pra mim. Aí eles descontaram tudo, eu não recebi foi nada."(Ana)

"Ixi, minha filha, eu tinha 7 anos.(Comecei a trabalhar) Em casa de família mesmo. (Sempre) É, nas casas de família. Lá eu trabalhava assim todo dia, né?! Eu praticamente morava na casa. Aí, eu trabalhei até os 15 anos, depois fui pra outra cidade de lá mesmo eu fiquei trabalhando. Então comecei a trabalhar no Piauí e depois foi pra Goiânia, sempre trabalhando nas casas de família." (Neuza)

"Sou daqui mesmo, do Goiás. Nasci em Planaltina. Eu comecei a trabalhar com uns 14 pra 15 anos, quando eu fui estudar, fazer meu segundo grau, à noite, aí comecei a trabalhar como doméstica. Depois eu trabalhei em loja. Quando eu fiquei grávida eu parei de trabalhar porque não tinha com quem deixar ela (filha de 4 anos). Aí depois que ela ficou maiorzinha eu voltei a trabalhar, mas aífazendo faxina. Não era de doméstica não (não tinha carteira assinada). Trabalhei de vendedora com carteira assinada, mas de doméstica mesmo não. Completei o segundo grau. Só, tenho essa filha de 4 anos. E já tá bom demais. Quero mais não." (Bete)

O início precoce no mercado de trabalho se mostrou necessário para essas mulheres e naturalizado na lógica do meio rural, pois eram membros de famílias de classe popular que viviam em situação de precariedade, com muitos irmãos e grandes dificuldades financeiras. As diaristas relatam seu contexto familiar:

"Tenho muitos irmãos, bem uns oito. A gente trabalhava na roça. Todos os filhos ajudavam, Ave Maria, era com uma inchadinha lá, minha filha."(Ivone)

"Meus pais trabalhavam de roça. Tenho, nós somos treze irmãos. Nós somos 6 mulheres e o restante é homem. Quando eu trabalhava... Até os 15 anos, a gente trabalha por conta dos pais da gente, né, que quer que a gente trabalha naquela família. Então, tipo assim, pra ajudar. Nessa época que eu trabalhava lá, eu nem recebia salário. Eles botavam eu pra trabalhar lá, dizendo que iam ajudar meus pais. Que meus pais eram bem pobrezinho. Aí, trabalhavam de roça, né?! Aí eu ia trabalhar e ganhava casa e comida. E dizendo eles que tavam ajudando meus pais. Mas não me pagavam nada."(Neuza) 
Comumente, o trabalho em serviços domésticos começa a ser exercido desde cedo, por crianças que vêm do interior para trabalhar em "casas de família" como uma estratégia para sua própria sobrevivência. Essa migração de crianças ocasiona grandes perdas no sentido educacional e de cidadania. Além disso, as crianças submetidas ao trabalho doméstico ficam expostas desde cedo à discriminação, à humilhação, ao isolamento e à violência física e sexual (AMORIM, 2008). O trânsito dos contextos rurais para o urbano mescla espaços e temporalidades e revela processos que não são estanques ou duais, mas demonstram contextos processuais onde corpos, sentidos, afetos, práticas violentas se entrecruzam e se formam.

De acordo com o Decreto ${ }^{\circ} 6.481$ de 12 de junho de 2008, o trabalho doméstico é uma das formas mais comuns e tradicionais de trabalho infantil e está entre as piores formas de ocupação a que se pode submeter crianças e adolescentes. São atividades que mesmo realizadas no âmbito do lar, violam direitos de crianças e adolescentes à vida, à saúde, à educação, ao brincar, ao lazer e ainda acarretam prejuízos que comprometem o seu pleno desenvolvimento físico, psicológico, cognitivo e moral (DIAS; ARAUJO, 2013). Ao lado de seus pais e mães, em contextos populares, a formação das crianças passa por vivenciar atividades que as formam como sujeitos em suas localidades e famílias, aprendem um ofício e a lida familiar, no entanto, quando transitam para outros contextos, essas meninas pardas e negras são recebidas muitas vezes pelo racismo e preconceito, assim, o trabalho não é mais uma atividade formativa, mas de exploração e violência.

Com relação ao estudo, três delas não chegaram a completar o ensino fundamental: "Eu estudei muito pouco!" (Ana). "Estudei até a 4a."(Neuza)."Eu nunca saí da $1^{a}$ série. Fiz só a primeirinha! Esse tempo no Nordeste era muito ruim, viu? Não tinha escola também. Quando aparecia a escola, a gente chegava lá era só pra dormir, porque tava cansada de tanto trabalhar." (Ivone).

Inseridas em "casas de família" que as reconheciam como trabalhadoras, o trabalho era algo distinto do lazer, das brincadeiras e das escolas. E não havia escolha entre estar nas brincadeiras ou escola, tendo em vista que elas estavam restritas ao trabalho, que em algumas situações era o "trabalho escravo", como elas afirmam, pois a remuneração se restringia ao local para dormir, à comida e às roupas. Desse modo, essas meninas estão nas estatísticas de um segmento com baixa escolaridade, o que significa dificuldade para elas conseguirem outro trabalho, permanecendo como trabalhadoras domésticas nessas casas, sem nenhuma garantia de direitos trabalhistas e com uma grande jornada de trabalho. Destarte, pode-se inferir que o binômio baixo grau de escolaridade/ausência de capacitação profissional é fator condicionante para a exclusão das diaristas de outros campos profissionais, uma vez que estas vivem em uma época de crescente especialização das profissões e de maior exigência quanto à formação escolar, sendo que para a inserção em grande parte dos espaços socio-ocupacionais, exige-se, no mínimo, a conclusão do ensino médio (PRISCO, CARVALHO; GOMES, 2013). Suas histórias de vida explicam por que suas vidas se restringem a essa ocupação, a esse grau de escolarização. 
Questionadas sobre a satisfação com seu trabalho e a vontade ou possibilidade de mudança de emprego como diaristas hoje elas responderam:

"Gosto (do meu trabalho)! É o que tem! (rindo) Hoje em dia você tem que agarrar o que tem, né?! Por que tá difícil. Hoje em dia você segura o seu! Sei lá, a gente chega numa certa idade que a gente nem sonha mais, nem dá tempo de sonhar, sonha mais quando a gente é novo, né?! Você quando é nova tem sonho de ter um carrinho, de ter um bom empreguinho e só tem sonho bom, mas a gente chega numa idade assim que você já sonhou tanto que nem sonha mais." (Ivone)

"Gosto (do meu trabalho). É o que eu sei fazer, né?! Eu não sei, nunca parei pra pensar (em trabalhar com outra coisa)". (Neuza)

"Gosto (do meu trabalho). Eu gosto muito de cuidar de casa. Eu gosto! Por enquanto não (não tenho vontade de fazer outra coisa). Por enquanto pra mim tá bom. Eu quero até mais. No caso, os dias que eu tenho livre, eu queria preencher." (Bete)

O espaço da identidade, pertencimento social, é criado e passa a ser valorado positivamente mais adiante, veremos como uma rede de apoio se forma entre essas mulheres permitindo subverter o contexto de exclusão em que se encontram. Um estudo sobre as representações do trabalho informal e dos riscos à saúde entre trabalhadoras domésticas e trabalhadores da construção civil na cidade de Salvador, Bahia, apontou que para as trabalhadoras, a baixa escolaridade, o medo do desemprego e a falta de opção são fatores que impossibilitam a mudança de ocupação e levam à aceitação do trabalho doméstico (IRIART, 2008). Em outro estudo sobre as trajetórias ocupacionais das diaristas atuantes na região de Santa Catarina, foi verificado que, em geral, elas não apresentavam planos estruturados relativos à sua vida laboral futura e que, embora tenham relatado gostar de atuar como diarista, isso não significava necessariamente que pretendiam permanecer nessa ocupação por longo prazo (COUTINHO et al., 2013).

As falas das diaristas mostram como as dificuldades estruturais estão inseridas nas trajetórias dessas trabalhadoras desde sua infância, gerando consequências que perduram por toda a vida, assim como afirma Monticelli (2013), "uma vez inseridas ainda crianças no trabalho doméstico remunerado, as possibilidades de sair dele são bem pequenas, prejudicando seu futuro educacional e limitando suas possibilidades trabalhistas".

Para muitas delas a fase da juventude foi um período difícil, em que tiveram que enfrentar episódios de preconceito e humilhação. Uma delas relatou em sua narrativa episódios racistas vivenciados nas casas onde trabalhou: "Quando eu comecei a trabalhar... Por que eu trabalhava pra uma família que era muito branca, né?! Aí, eles sempre me chamava de negra. Eu tinha uns 10 anos" (Neuza).

A distância social baseada em aspectos raciais ainda continua moldando formas de poder no cotidiano do emprego doméstico, aparecendo de forma sutil, criando conflitos que são encobertos pelo âmbito privado (FREITAS, 2010). Em 2014, 17\% das mulheres negras eram domésticas e apenas 28,6\% delas trabalhavam com carteira assinada (PINHEIRO et al., 2016). Racismo, machismo e desigualdade de classe marcam essa situação, não ter carteira assinada 
ou seus direitos respeitados está embasado em argumentos que veem o trabalho doméstico como naturalizado no feminino, então, não deve ser remunerado. Além disso, essas mulheres vivenciam o racismo replicado do período da escravização e sujeição dos corpos negros e pardos, quando as mulheres negras estavam ali para servir.

É o que transparece na fala de Ana sobre sua experiência na primeira casa onde trabalhou: "Eu fiquei lá 1 mês e alguma coisa. Eu falei: Sabe de uma coisa? Eu não vou ficar aqui mais não! O pessoal tá me humilhando demais!". Ivone também relata: "Eu já trabalhei em casa que os patrões eram bem assim carrasco, tipo: empregada tem seu canto; empregada não vai na mesa, só pra trabalhar; empregada não se senta perto do patrão.” As domésticas se sentem humilhadas sempre que veem a distância social entre si e suas contratantes ser reforçada por meio de atitudes diferenciadoras violentas desencadeadas pelas patroas e o racismo é o pano de fundo dessa estrutura (FREITAS, 2010). A humilhação é quase uma regra do cotidiano do emprego doméstico, pois é proveniente da "desigualdade de poder entre os agentes sociais que se prendem ao emprego doméstico" e "do forte grau de servidão que a ocupação impõe às trabalhadoras" (FREITAS, 2010).

Algumas delas também sofreram assédios advindos de seus empregadores, e como elas eram migrantes e quase não tinham mais contato com seus familiares ou com outras pessoas que pudessem lhes apoiar, tiveram que enfrentar essas situações sozinhas. Neuza relata: "Nessa casa mesmo onde eu trabalhava (entre seus 10 - 15 anos), o meu patrão, ele vivia me assediando. Ele falava as coisas pra mim, ficava falando...(Constrangida). Só que eu, graças a Deus, nunca dei moral pra ele".

As violências físicas e sexuais são eventos mais frequentes entre as mulheres e, principalmente, com trabalhadoras de baixa qualificação profissional, podendo acarretar diversos problemas de saúde como apontam os estudos epidemiológicos mundiais, que avaliaram os efeitos do assédio sexual sobre a saúde e mostraram que o alcoolismo, transtornos mentais e de apetite, distúrbios do sono e baixa autoestima são consequências frequentes reportadas pelas mulheres vítimas desse crime (AMORIM, 2008).

Devido à questão da subordinação aos patrões, da discriminação no trabalho e das questões de gênero e de racismo, o trabalho em serviços domésticos apresenta as condições propícias para ocorrência do assédio sexual laboral e, embora o reconhecimento legal deste crime tenha contribuído para a não discriminação no trabalho, a Lei do Assédio Sexual (Lei 10.224/01) não consegue abranger todas as ocupações, permanecendo desprotegida a trabalhadora doméstica diarista, por não possuir vínculo profissional (AMORIM, 2008).

Muitas delas enxergaram no casamento a possibilidade de sair das casas onde trabalhavam e conquistar seu próprio espaço com a ajuda do companheiro. Enquanto que por um lado o matrimônio lhes permitiu maior liberdade, por outro, lhes acrescentou uma carga de trabalho maior, pois elas passaram a ter obrigações como esposa, mãe e como dona de casa, o que resultou em múltiplas jornadas de trabalho para elas, que não contam com a ajuda masculina nas tarefas 
domésticas. De acordo com Ivone, ela faz "serviço dobrado" ao aliar o serviço nas casas das patroas com sua casa. Neuza explica que não há ninguém para ajudá-la em casa: “Assim, tem o meu marido e meu filho, mas não me ajudam, não. Eu faço o serviço todo aqui e quando eu chego em casa tem que fazer tudo lá". Por sua vez, Bete relata: "Aí aqui (na minha casa), eu faço sozinha. Ninguém me ajuda. Principalmente ele (Marido) que não me ajuda mesmo".

A violência doméstica também perpassa a vida dessas mulheres. Elas enfrentam um relacionamento no qual não existe apoio e, frequentemente, vivenciam situações de opressão, traição e violência, além de sofrerem ao ter que criar seus filhos neste contexto. Ana fala de sua experiência:

"Depois que eu arrumei esse agora (atual companheiro) ficou até pior. Tenho um casal (de filhos) com ele. De uma hora pra outra ele sumia, viajava. Minha menina tá dando trabalho por causa dele. Dou conta de mandar embora não, por que agora tá até perigoso a gente mandar embora. O jeito que tá ruim, né, os homens estão perigosos. Eles não querem separação, não. Por que eu me separei dele, né? Quando teve uma confusão eu me separei dele e agora não dá certo não. É perigoso. Eu fico preocupada. E na confusão, minha filha, eu não falei nada com ele, não falei nem que ele era feio, não falei nada. Só vi ele de lá pra cá, metendo a mãozona em mim. Eu tava lavando o chão, só vi ele batendo na minha cabeça. Aí mandou eu sair de casa: "Vai sai daqui!'”'(Ana)

Nesses casos, elas tiveram que sair de suas casas com os filhos, sem condições financeiras, e procurar ajuda com familiares, amigos, vizinhos e patrões, já que não puderam contar com as garantias legislativas, pois, apesar de a violência doméstica ser caracterizada como crime no Brasil, elas não obtiveram assistência social ou policial, preferiram construir suas próprias estratégias para enfrentar a situação. Essa realidade trouxe consequências sérias para o bemestar destas famílias, tais como o medo, o esgotamento emocional e a depressão. A filha de Ana sofre de um problema psiquiátrico grave que ela acredita ser resultado dessa situação com o marido. Ana foi chamada pela escola para ver a filha que estava se cortando no banheiro da escola, ela estava fazendo diária longe do local onde vive e sua filha estuda. Ana pediu a sua filha mais velha para ir à escola, mas ela estava trabalhando, sua filha conseguiu que sua cunhada fosse ver o que estava acontecendo. Ela levou a filha de Ana para sua casa, para aguardar o retorno da mãe. Essas mulheres contam com essa rede de apoio para cuidarem de si e de seus filhos quando estão no trabalho ou em outras situações.

A violência doméstica é apontada como fator de risco para a doença mental, depressão, suicídio, entre outras consequências físicas, podendo acarretar transtornos na vida social por abandono material, que pode resultar na desagregação familiar. E, por isso, é reconhecida como um problema de saúde pública que demanda atenção e intervenção do Estado para seu enfrentamento, sendo a ausência de ações do Estado que garanta a segurança das mulheres um fator agravante, que implica em sérias consequências para a saúde das vítimas (ALBUQUERQUE; FREIRE; PASSOS, 2014). No caso de Ana, quando se viu expulsa de casa pelo marido, ela 
acessou essa rede de apoio familiar, de vizinhança e amigas para se reestruturar, isto é, alugar um barraco, ter os móveis em casa e apoio para cuidar dos filhos. No entanto, Ana retornou à vida com o companheiro, apesar dos protestos de sua filha. Ana tem medo que o marido a mate.

Sobre essa rede de apoio e cuidado, vale enfatizar o caráter da dádiva que ela representa em contextos populares, nos termos de Mauss (2003). Essa rede é acessada em uma lógica do dar, receber e retribuir, por essa rede circulam pessoas, cuidados, informações, objetos, os quais se constituem em práticas que permitem a essas mulheres subverterem contextos de opressão. Especialmente, nos casos relatados aqui, essas mulheres são acolhidas e acolhem. Uma rede feminina em contexto popular se apresenta acima dos estigmas, violência e imposições, reforçando o controle sobre a vida. E essa troca é coletiva, não se restringe aos indivíduos, mas aos arranjos familiares que elas constituem.

\section{Práticas Cotidianas na Faxina}

As trabalhadoras contaram que, geralmente, o tempo gasto para se chegar ao trabalho é de $1 \mathrm{~h} 30$ a $2 \mathrm{~h}$, o que torna a locomoção muito cansativa. Na maioria das vezes, elas precisam pegar dois ônibus para chegar ao seu destino. Elas mencionam a dificuldade em conseguir chegar ao local de trabalho quando os funcionários do transporte público entram em greve. Também demonstram o medo e a insegurança que sentem ao ter que estar muito cedo nas paradas de ônibus. Elas relatam:

"Eu trabalho todo dia, né?! O meu horário de chegada é as 8h e saio às 16h. Moro em Águas Lindas e Acordo às 4 h30 para chegar às $8 h$. Vou dormir 23h-23h30. Durmo pouquinho!"(Neuza)

"Eu trabalho em três casas. Trabalho dois dias num, dois dias no outro e um dia em outro. Moro em Luziânia. Olha, na verdade a gente fala que mora em Brasília e dorme em Luziânia, né?! É tranquilo, mas a gente viaja muito! Só de ônibus a gente fica o quê... São duas mais duas (Contando nos dedos), são 4 horas de ônibus, rodando, pra ir e pra vim. 2 horas pra vir e 2 horas pra voltar. É, é difícil por causa disso, dos ônibus. Mas, as paradas de ônibus é cheio de ladrão. Às vezes a gente tá vindo no ônibus e as pessoas dizem: acabei de ser assaltada! Perigoso! Eu mesma já fui assaltada duas vezes em parada de ônibus. Acordo às $3 h 30$ da manhã. Vou dormir com as galinhas. Vou dormir 20h - 21h, pra poder acordar $3 h 30$ da manhã. Eu acordo 3h30, mas saio de lá 4 h40 (De Luziânia). Eu chego aqui 6h e pouco (Na Asa Sul). Eu saio daqui 15h30. 15h/15h30 eu vou embora. Pegar o ônibus de volta. É, essa é a pior parte! Trabalho de segunda a sexta. Sábado não."(Ivone)

"Saio do Pedregal (Bairro do Novo Gama) pra poder chegar aqui na Asa Sul (Bairro de Brasília) durante a semana, agora, eu levanto 4 horas da manhã, faço café... Tem vez que eu deixo a comida pronta pra eles (pros filhos). Saio 5 h20 da manhã. Deixo a comida pronta! Eu deixo o café pronto, lavo as vasilhas, passo pano no chão se der tempo, aí eu boto o lixo lá fora e saio. 5 h20 eu vou pra parada e 5 h30 passa o ônibus. Aqui (Asa Sul) eu chego umas 8h. (Após encerrar a faxina) 
Eu chego na parada umas 17h, é longe, é $1 \mathrm{~km}$ e meio! Eu sigo pra Rodoviária, na Rodoviária pego umas 18h/19h. Chego em casa quase na hora do jornal."(Ana)

"Eu faço faxina no DF. Faço no Gama, na Samambaia e na Asa Norte. Trabalho de segunda a sexta. Não é todos os dias. Assim, numa semana eu tenho... na verdade eu tenho em uma semana quatro dias e na outra também quatro dias, só que muda. Uma semana eu folgo na quarta e na outra semana eu folgo na segunda. Quer ver, eu trabalho um, dois, três... cinco casas diferentes! Depende do tamanho da casa, aí varia, eu tenho faxina de $R \$ 120,00$ a 150,00. Meu horário é eu que faço. Só tem uma que eu chego cedo, por que ela fica me esperando pra ela sair pra ir trabalhar. Então é o único lugar que eu chego por volta de 6h30, 6 h45 da manhã. Na Samambaia eu vou de carro. Saio de casa por volta de 5h30,5h40. A casa que eu trabalho na Asa Norte, eu vou de ônibus pra lá. É umas 1 hora e meia, 2 horas pra chegar lá. Aí, no caso, na Samambaia, no Gama... Aonde eu faço no Gama é na Ponte Alta, aí não tem ônibus. Aí eu teria que pegar ônibus pra Taguatinga, descer na BR e ir andando. Não é muito longe, não. Que dá, dá! Mas eu não faço. Como o valor que boto na faxina dá pra mim pagar a gasolina, então eu vou de carro. Que aí eu saio daqui por volta de 7h30. Então eu faço meu horário. E eu terminei eu venho embora. Eu não tenho que cumprir horário. Ah! ficar até $18 \mathrm{~h}$ porque eu tenho que trabalhar 8 horas/dia, não! Então eu faço meu serviço e tchau. Se eu terminar $13 \mathrm{~h}$ eu vou embora $13 \mathrm{~h}$, se eu terminar $17 \mathrm{~h}$ eu vou embora 17h. Eu que faço meu horário. Não preciso chegar muito cedo e também não saio tarde. Depende do meu ritmo. A média do serviço que eu saio é assim $17 \mathrm{~h}-17 \mathrm{~h} 30$. .'(Bete)

Cada diarista possui sua forma particular de organizar e efetuar a limpeza das residências. O tempo despendido para execução da faxina também varia e segue o acordado com os contratantes. Elas explicam sua rotina de limpeza:

"Quando eu chego aqui de manhã, passo a roupa tudinho, faço a comida e dou a comida do Pedro (Criança que ela cuida) e limpo a casa. Assim, umas 1h30/2h, que o Pedrinho já foi pra escola, fica mais tranquilo, que ele não deixa eu fazer nada. Aí eu vou passar pano na casa e ainda tenho que lavar lá de fora (Garagem)."(Neuza)

"Agora eu tô fazendo assim, chego lá na casa, limpo a casa todinha. Não mexo em roupa muito mais não. Aí eu chego lá abro as portas da casa toda. Quando eu chego lá, a mulher já sai: Eu tô saindo e não tenho hora de chegar! Só chega lá pra meio-dia/ uma hora. Aí vem eu pra cuidar da casa toda, aí vem o banheiro, que são oito banheiros. Tô falando, as casas do Jardim Botânico é grande! Aí eu vou lá pro banheiro, limpo logo os banheiro. Que eles não usam muito os banheiro, só uns dois que eles usam mesmo, que os outros só quanto tem visita. Aí eu vou pra casa, limpo a casa todinha, venho pra cozinha 11 h30 cuidar do almoço. Quando dá meio-dia o homem chega: Tá pronto? Que o primeiro que almoça é ele, a mulher não almoça, não. Primeiro que chega é o patrão, pra almoçar. Aí ele mesmo vai nas panelas e tira a comida. A mulher chega lá pras 2 horas, 2 horas que ela vai almoçar. Aí eu arrumo a cozinha, passo pano no chão e vou lá pra roupa, passar roupa, e quando dá dez pras cinco (da tarde) eu guardo a roupa lá pra cima, aí eu me arrumo e saio pra parada."(Ana) 
"Quando chego na casa tenho que fazer tudo! Eu lavo o banheiro, tiro a poeira, limpo janela, lavo o chão, algumas eu passo roupa, outras eu lavo roupa e passo. É serviço de casa só não faço comida! Na casa de ninguém eu faço comida. Eu não tenho lugar de só passar roupa. Eu no caso tenho três casas que eu passo roupa, né? Já é combinado o valor tudo incluso. Não, só passar roupa não. Aí eu faço o serviço da faxina, de cuidar da casa, e depois eu passo a roupa."(Bete)

O tempo para chegar às casas, fazer render o serviço e seguir na longa jornada de retorno para casa é calculado, Ivone explica: "Eu almoço correndo e volto pro meu trabalho pra eu ir logo pra casa. Não tiro uma hora para almoçar não, tiro não! Tem gente que tira, mas é difícil. Tem gente que prefere ir direto logo pra fazer o serviço, pra ir embora logo".

Para estas mulheres, momentos de lazer e diversão são inexistentes: "Não tenho. Quase não tenho não, não tenho! A única coisa que eu saio assim é só pra igreja mesmo. Final de semana eu vou pra missa e fico em casa também. Descansar!" (Neuza); "Tem igreja, mas eu nem vou. No final de semana você fica tão cansada que ir pra igreja você fica sem coragem de ir." (Ivone); "Sábado e domingo eu fico em casa. Vou resolver minhas coisas, vou no mercado fazer compra. Aí vou lavar roupa, vou lavar banheiro. É assim final de semana! Não saio, não." (Ana); "Eu procuro não trabalhar no sábado, que no sábado e domingo eu tô em casa. Mas a gente não sai. É muito raro! É opção minha não fazer faxina no sábado. Faço aqui (na própria casa)!” (Bete).

A vida nas cidades que essas mulheres experienciam também é marcada pela falta de opções de espaços de encontro, esses se dão, para as mulheres, entre vizinhanças, conversas nos portões, nas casas e igrejas. Os homens se encontram nos bares conforme relataram. Essas mulheres trataram das dificuldades que enfrentam cotidianamente para conciliar o trabalho e a criação dos filhos:

"Eu botava uma pessoa pra cuidar. Pagava a pessoa que ficava com os meninos e ainda levava comida pra eles comer. Tem vez que o dinheiro ia quase tudo. $R \$ 80,00 / R \$ 60,00$ ! Era a metade da diária. Cansava de deixar gente. Quando chegava do mesmo jeito que eu deixava a comida, ficava. O bichinho tava sem comer, que eles não sabiam mexer em nada, né?! Outros judiavam com os meninos, quando dava fé, de noite os meninos tavam lá numa casa lá embaixo, com frio, com os peito de fora, que não tinham levado blusa. Falei: Não, não aguento! Aí eu despachava a menina que não dava certo. Aí botava outra, não dava certo. Aí eu não aguentava: Vocês vão se virar agora sozinho, que eu não vou mais pagar! Passei a deixar eles sozinhos em casa." (Ana)

"Que ela (filha de 4 anos) fica na escola, o dia todo. No caso ela entra às 7 h e fica até 18h, 18h30, que é o horário que eu costumo pegar ela. É tempo integral o colégio! Se ela fica doente, aí no caso tem que ser eu. Não faço serviço. Aí eu mato serviço. No caso, eu ligo avisando. No começo, antes dela ir pro colégio, ela ia comigo. Em algumas faxina ela ia comigo. Em outras eu deixava ela com a esposa do meu sobrinho.” (Bete)

Uma das diaristas relatou que precisou entregar uma de suas filhas para outra família criá-la, pois a criança necessitava de um maior cuidado que ela não podia oferecer uma vez que 
precisava trabalhar o dia todo para garantir o sustento do restante da família: "Aí o que eu fiz: pra não tá a minha filha sofrendo por causa de ninguém eu tenho que dar! Dei pra uma mulher que eu nunca conheci, mas hoje ela trata bem a Júlia e a Júlia ajuda ela" (Ana). Acionando sua rede de apoio, Ana ficou sabendo que essa mulher queria ter filhos e entregou sua filha. Ela convive com essa filha que, hoje, está adulta.

Andrade (2016) afirma que o cuidado com os filhos pode ser um obstáculo concreto à participação feminina no mercado de trabalho, sendo o acesso à creche indispensável para que as mulheres possam exercer atividades remuneradas. No entanto, no caso das mulheres que participaram deste trabalho, essas instituições não existiam, elas deveriam dar conta sozinhas das famílias e do trabalho fora de casa.

A relação com o patrão é um aspecto importante na atuação das diaristas e pode levar à valorizar ou não do trabalho (COUTINHO et al., 2013). Algumas entrevistadas destacaram a valorização e a relação de confiança estabelecida com os esses: "[...] esses patrão que eu tenho agora são tudo gente boa, deixa a gente à vontade. Também são emprego de 30, 35 anos, que eu luto com família assim. É amizade! Parece irmão!" (Ivone).

Todas as situações vivenciadas e as experiências adquiridas nas casas onde essas mulheres trabalharam moldaram suas escolhas individuais em torno do trabalho realizado como diarista e como mensalista. Monticelli (2013, p. 137) afirma que "as desilusões, as privações, a violência, as angústias, os medos não estão apenas contidos como alegorias em uma narrativa, mas são instrumentos de transformações pessoais e sociais para cada uma dessas mulheres". Desse modo, as escolhas são pautadas pela maior renda, pelas tarefas que precisam executar, pelo cansaço, pela autonomia e pelas relações harmoniosas e afetivas que são construídas com os empregadores. Isso revela estratégias interessantes de terem controle sobre suas ocupações de diaristas, que são marcadas pela precariedade e não reconhecimento trabalhista. Assim, essas mulheres, ao longo do tempo, vão encontrando meios de controlar suas relações trabalhistas, na ausência de proteção estatal.

Ivone explica suas escolhas:

"Eu sempre trabalhei em casa de família mesmo, fazendo de tudo. Mas, eu passo mais roupa. Faço faxina também, mas passo mais é roupa. Nunca trabalhei com carteira assinada, não. Eu trabalho por diária. É por minha conta. Eu pago meu INSS. Se acontecer alguma coisa comigo, eu vou levar prejuízo por que eu tô trabalhando por minha conta. Eu só trabalho 1 dia ou 2, aí não tenho direito a nada. Minha carteira tá limpinha! Nunca tive carteira assinada. Nem quero ter nesse trabalho, prefiro trabalhar como diarista ganho mais (Rindo). Você trabalhando assim você ganha mais, por que você passa o mês todinho pra ganhar um salário, né, $R \$ 800,00-R \$ 900,00$. E você trabalhando por diária você ganha mais. Você ganha o dobro, por exemplo. Mas tudo tem seu preço, né?!" (Ivone)

Sobre a rotina de seu trabalho, Ivone relata:

"Ah, sinto cansaço no meu trabalho, todo mundo sente! Peso, nem tanto. Cansaço é mais por 
causa das viagem que a gente faz nesses ônibus, né?! Aí a gente chega em casa já tão cansada, que você olha pra suas coisas e não dá nem vontade de fazer, mas você não vai ficar no desmantelo, aí vai e faz. Tem dia que nem janta eu faço de tão cansada. É porque quando a gente vai dar faxina a gente tem que fazer de tudo, né ?! Então você termina você fica com suas costas doendo. Muito dolorida às vezes, né?!" (Ivone)

Ana trata de suas relações no trabalho e as escolhas:

"Nunca tinha trabalhado fixado, só na diária. É complicado pra pessoa, né?! Porque o pior é que não tem jeito de encostar, né?! Não tem jeito de aposentar, né, na diária. Se não pagar do seu lado, não tem jeito! Hoje é difícil trabalhar na diária. Se não pagar o seu INSS... Se pagando já complica, né, imagina não pagando! Porque na diária, de um dia pro outro a pessoa fala: Ah não quero mais! É! Diária a gente perde, né?! É, por isso que eu tô falando... Eu trabalhava, chegava no final de ano, cadê? Ôh! Eu achei maravilhoso, agora, ter a carteira assinada. Vou completar 3 anos já, né?! Recebo décimo terceiro, férias...Esse ano já peguei 20 dias de férias. Ano passado eu peguei 15. Vendi, vendi o resto das férias. Então ficou melhor. Lá não tem menino que me incomoda, só tem eu, ela e o marido dela."(Ana)

Neuza fala sobre a escolha em ser diarista ou mensalista (carteira assinada):

"De positivo (do trabalho), a gente trabalha porque tem que trabalhar e gosta de fazer, né?! E tem alguma coisa pra fazer todo dia, né, pra fazer aquilo. É, eu prefiro carteira assinada. Porque diarista é muito cansativo. A gente vai ficando mais velha, não aguenta mais, não. É melhor, porque assim você recebe por mês. Tem como contar, né?! E diarista não. Se você não for trabalhar, você não ganha. Se você adoecer, não tem com o que contar."(Neuza)

Bete explica os motivos que a faz preferir ser diarista:

"É, porque eu ganho muito mais como diarista do que se eu for trabalhar de doméstica mesmo, porque ter um salário $X$ é bem menos do que eu tiro como diarista, eu tenho faxina de $R \$$ 120,00 a 150,00. A única vantagem de carteira assinada é que você tem férias, décimo terceiro. Se você ficar doente você tem aquele respaldo, mas fora isso, o salário é bem menor. Você ganha bem menos! Não (pago INSS)! Se acontecer alguma coisa tô no sal, né?!’(Bete)

A partir desses argumentos, fica evidente que, por um lado, deseja-se trabalhar de forma regulamentada, pela segurança na velhice com a aposentadoria, por receber todo fim de mês, além de férias, décimo terceiro salário, mas, por outro, as perdas estão em permanecer mais horas no serviço, com constante supervisão dos patrões, além de ter descontados no salário os tributos sociais, ocasionando a redução do mesmo.

\section{Percepções de Saúde}

O ambiente de trabalho das trabalhadoras domésticas pode apresentar riscos ergonômicos, físicos, químicos, biológicos e até os estressores ocupacionais, como as múltiplas responsabilidades, as longas jornadas e, por ser esse um espaço que escapa da fiscalização, acaba 
permitindo formas de violência, coerção e isolamento, que as colocam em situação de risco para outros transtornos (AMORIM, 2008). Além desses riscos, os acidentes de trabalho, sintomas de depressão, ansiedade e outros transtornos mentais comuns estão associados ao emprego doméstico (LUDERMI, 2000; PINHO; ARAUJO, 2012).

É difícil para as trabalhadoras domésticas perceberem o seu trabalho como possível causa de adoecimento, devido à similaridade com as atividades desenvolvidas em suas próprias casas e por esse tipo de trabalho estar inserido em uma dinâmica de sofrimento, baseada, sobretudo, na dor moral, circunscrita na vida social dessas mulheres, e que reflete a forma como a sociedade (des)valoriza e concebe essa ocupação (TAMANINI, 1997; IRIART, 2008). No entanto, elas reportam alguns acidentes, como escorregões e quedas decorrentes do piso úmido e ensaboado, cortes nas mãos ao lavar a louça ou cozinhar e pequenas queimaduras ao passar roupas: "Escorregar a gente escorrega, de vez em quando a gente queima, mas é coisa de leve. Isso aí acontece muito, você cai, levanta, fica com dor no corpo." (Ivone). Mas, apesar da dor e dos ferimentos, elas os consideram de baixíssima gravidade, não as impedindo de continuar a realização de suas tarefas, sem receber nenhum tipo de atendimento ou ajuda: " $E$, cortezinho de dedo às vezes, mas nada que me impedisse de trabalhar" (Neuza); "Já caí. Mas não foi coisa de não ter que ir trabalhar no dia seguinte porque eu me machuquei. Só o roxo mesmo, né, mas de não ter que ir, não!" (Bete).

Ao serem questionadas sobre o uso de equipamentos de proteção, elas reportaram não usar por considerar que estes equipamentos lhes atrapalham na execução de suas atividades: "[...] que eu não uso luva. Eu não gosto de fazer nada com luva." (Bete); "É difícil usar assim, eu não uso não. Às vezes a gente usa por que o sabão tá comendo as mãos. Eu vejo as empregadas dizendo que tá usando luva por que o sabão tá comendo as mãos, aí usa, mas é difícil. [...] eu nem gosto. Eu prefiro ficar com os calos nas mão." (Ivone). Notou-se também que elas não percebem o uso desses objetos como algo que poderia evitar muitos dos pequenos acidentes sofridos.

Essas trabalhadoras, no entanto, apontaram a sobrecarga de trabalho como causa de adoecimento: “[...] é serviço pesado, né?!” (Bete); "É porque quando a gente vai dar faxina a gente tem que fazer de tudo, né, então você termina você fica com suas costas doendo. Muito dolorida às vezes." (Ivone). Um dos motivos mais frequentes de procura médica por parte das trabalhadoras domésticas é a dorsalgia, uma patologia que promove a queda da qualidade de vida e absenteísmo ao trabalho (RAMOS, 2003).

A dupla jornada de trabalho, que leva a trabalhadora doméstica a repetir, na sua casa, as mesmas atividades realizadas na casa dos patrões, também deve ser levada em consideração como um fator de risco (IRIART, 2008). Associado a estas questões, está o tempo para executar uma grande quantidade de tarefas e a consequente ausência de um momento para descanso ou para as refeições: "eu almoço correndo e volto pro meu trabalho pra eu ir logo pra casa." (Ivone).

As entrevistadas mencionaram dores de coluna, crises de asma e alergia a produtos de limpeza como problemas de saúde associados ao trabalho doméstico:" $E u$ tô tendo muito 
problema de alergia. Os produtos de limpeza tá me deixando muito... a poeira também. Aí eu tô tendo muita crise de alergia, frequente." (Neuza); "Eu tenho problema de asma. Já tem uns 10 anos ou mais. Mas é assim, eu vivo controlada por remédio. Trabalho, às vezes dá o cansaço, teve uns tempos que eu quase não dava conta de trabalhar por causa dos problema de saúde meu."(Ivone).

As diaristas também revelam as dificuldades que encontram para acessar os serviços de saúde próximos as suas residências nas cidades do entorno do Distrito Federal, preferindo, quando possível, deslocar-se até os centros de saúde e hospitais de Brasília:

"Eu me tratava de asma lá (posto de saúde em Luziânia), só que não tinha recurso, eu vim achar recurso aqui em Brasília. [...]é difícil conseguir uma consulta, passei 1 ano pelejando[...] Aí eu vim pra Brasília fazer o tratamento[...]”(Ivone)

"Aqui, às vezes que ela (filha) ficou doente, a gente levou no hospital aqui (referindo-se ao Hospital Municipal de Valparaíso), mas não tinha médico, aí a gente foi pra Asa Sul, ali no HMIB (Hospital Materno-Infantil de Brasília). Ou no Gama, que também não tem médico, aí eu vou pro HMIB. Até que ela não é de ficar muito doente, mas se precisar aqui é difícil. Porque nunca tem médico, ou quando tem é clinico geral, não é pediatra. Já levei aqui, que ela tava doente, precisei, levei aqui mesmo e resolveu o problema porque não era nada grave, mas se for uma coisa mais grave aqui não resolve." (Bete)

Diante da falta ou da dificuldade de acesso aos serviços de saúde, seja pela inexistência de unidades ou de profissionais de saúde próximos a suas moradias, ou pela impossibilidade de conciliar os horários de trabalho com o do atendimento nos centros de saúde, essas trabalhadoras acabam utilizando chás e medicamentos por conta própria para resolver ou aliviar seus problemas de saúde.

\section{Considerações Finais}

Esta pesquisa não pretende estabelecer generalizações, mas deve ser compreendida como uma proposta de apresentar vidas em sua singularidade, uma tentativa de ter narrativas sobre o miúdo da vida e onde estruturas de desigualdade marcam corpos e pessoas. Está voltada para um olhar mais aguçado sobre a informalidade que marca o trabalho doméstico, especialmente, o modelo de diaristas.

As narrativas obtidas evidenciam o reconhecimento da desvalorização do trabalho informal e das trabalhadoras nessa situação e a consciência da sua invisibilidade social, política e moral, uma vez que se reflete na própria consideração do seu valor pessoal. Essas mulheres revelam em suas biografias como as desigualdades sociais as marcam, no gênero, na classe, na ocupação, no local de moradia e na raça.

Da infância à vida adulta, elas se encontram enfrentando esses marcadores sociais. São migrantes que vieram para a região da capital federal em busca de trabalho, acionando uma rede de compadrio que se efetiva no meio rural. Mas, no trânsito para a vida urbana, onde se 
estruturam determinadas práticas e relações de trabalho, elas caem em uma teia de exploração na infância e na vida adulta, por serem mulheres.

Ao constituírem suas famílias, algumas vivenciam a violência doméstica, sobressaindo em suas vidas a maneira como acionam uma rede de cuidado, feminina e baseada na dádiva, nos termos de Mauss (2003). Essa rede permite-lhes subverterem essa ordem de subalternização. Nessa rede de dádivas e contradádivas, onde circulam conhecimento, pessoas, objetos, tecnologias de cuidado, elas doam seus filhos, encontram pessoas que cuidam dos mesmos, encontram acolhida na violência doméstica, local de moradia e oferta de trabalho. Podemos compreender essa rede como uma estratégia de subversão, especialmente ao estabelecerem vínculos de trocas entre amigas, vizinhos e familiares.

Ainda no âmbito dessas estratégias de enfrentamento, foi possível compreender a partir das narrativas e práticas dessas mulheres que a informalidade como diarista acaba por ser uma estratégia de controle da violenta relação com o patrão/patroa. Como diaristas, elas fazem escolhas sobre a rotina no trabalho e sobre o tipo de patrão/patroa que pretende ter, criando uma maior rotatividade no trabalho, além de conseguirem manter pouco contato com os patrões/patroas. Por outro lado, situações de adoecimento e velhice não são contempladas como direitos trabalhistas e isso é revelador da fragilidade em que se encontram.

Não obstante, a ausência de políticas públicas, programas e ações que promovam a conciliação entre o trabalho e a vida familiar, impacta diretamente na condição de vida e saúde das trabalhadoras domésticas em diversos aspectos, desde a sua experiência de ter sido trabalhadora infantil doméstica, as suas possibilidades de formação educacional e de acesso à formação profissional, até o tempo dedicado ao lazer e aos cuidados de si e de sua família. Nas margens do Estado e de seus direitos como cidadãs e vivendo sob o jugo do racismo, machismo e desigualdade de classe, resta a essas mulheres criarem estratégias de cuidado, em uma rede de apoio marcada pelo feminino subvertendo a subalternização de suas vidas.

\section{Referências}

ALBUQUERQUE, A.S; FREIRE, M.F.S.; PASSOS, R.G. Violência doméstica e saúde das mulheres: uma análise da experiência do município de São Gonçalo. O Social em Questão, Rio de Janeiro, v. 18, n. 31, p. 117-136, 2014. AMORIM, A.M. Emprego em serviços domésticos e efeitos sobre a saúde. 2008. 96 f. Tese (Doutorado em Saúde Coletiva) - Instituto de Saúde Coletiva, Universidade Federal da Bahia, Salvador.

ANDRADE, T. Mulheres no mercado de trabalho: onde nasce a desigualdade? Estudo Técnico, julho de 2016. Consultoria Legislativa, Câmara dos Deputados, Brasília, p. 1-72.

BERNARDINO-COSTA, J. Decolonialidade e interseccionalidade emancipadora: a organização política das trabalhadoras domésticas no Brasil. Revista Sociedade e Estado, Brasília, v. 30, n. 1, p. 147-163, jan./abr. 2015.

BRASÍLIA. Consultoria Legislativa da Câmara dos Deputados. 2016. Disponível em: <http://bd.camara.gov.br/ bd/handle/bdcamara/29160> Acesso em: 22 mar. 2017.

BORIS, E. Produção e reprodução, casa e trabalho. Tempo Social, São Paulo, v. 26, n. 1, p. 101-121, jun. 2014.

BOURDIEU, P. Por uma ciência das obras. In: Razões Práticas: sobre a teoria da ação. Campinas: Papirus, 1996. p. 53-90. 
BRITES, J.G. Trabalho doméstico questões, leituras e políticas. Cadernos de Pesquisa, São Paulo, v. 43, n. 149, p. 422-451, mai./ago. 2013.

COUTINHO, M.C. et al. Todo dia uma casa diferente: trajetórias, sentidos e cotidianos laborais de diaristas. Universitas Psychologica, Bogotá, Colômbia, v. 12, n. 4 p. 1127-1140, out./dez. 2013.

DIAS, J.C.; ARAÚJO, G. S. (Orgs.). O Trabalho Infantil Doméstico no Brasil: avaliação a partir dos microdados da Pnad/IBGE (2008-2011). Brasília: Fórum Nacional de Prevenção e Erradicação do Trabalho Infantil, 2013.

FREITAS, J. B. Desigualdades em distâncias - gênero, classe, humilhação e raça no cotidiano do emprego doméstico. 2010. 220 f. Dissertação (Mestrado em Sociologia) - Programa de Pós-Graduação em Sociologia, Universidade de São Paulo, São Paulo.

HOOKS, B. Intelectuais negras. Revista Estudos Feministas, Florianópolis, v. 3, n. 2, p. 464-478, 1995.

IBGE. Censo Demográfico 2010. Disponível em: < http://censo2010.ibge.gov.br/> Acesso em: 02 mar. 2017.

IBGE. Estimativa Populacional 2016. Disponível em: < http://cidades.ibge.gov.br/v3/cidades/home-cidades> Acesso em: 02 mar. 2017.

IFG. Dados e Indicadores Econômicos, Sociais e Educacionais da Microrregião do Entorno de Brasília para Subsidiar a Atuação das Instituições Públicas de Ensino. Boletim de Conjuntura Econômica e do Mercado de Trabalho do Estado de Goiás. v. 1, n. 1, p. 114-144, out. 2012.

IRIART, J. A. B., et al. Representações do trabalho informal e dos riscos à saúde entre trabalhadoras domésticas e trabalhadores da construção civil. Ciências \& Saúde Coletiva, Rio de Janeiro, v. 13, n. 1, p. 165-174, 2008.

LEÃO, L. H. Trabalho escravo contemporâneo como um problema de saúde pública. Ciência e Saúde Coletiva, Rio de Janeiro, v. 21, n. 12, p. 3927-3936, 2016.

LUDERMI, A. B. Inserção produtiva, gênero e saúde mental. Cadernos de Saúde Pública, Rio de Janeiro, v.18, n. 6, p. 1571-1575, 2000.

MACEDO, R. Trabalhadoras e consumidoras: transformações do emprego doméstico na sociedade brasileira. Revista Política \& Trabalho, João Pessoa, n. 42, p. 311-333, jan./jun. 2015.

MANICA, D. Autobiografia, trajetória e etnografia: notas para uma Antropologia da Ciência. Revista Espaço Acadêmico, Maringá-PR, v. 9, n. 105, p. 69-77, fev. 2010.

MAUSS, M. Ensaio sobre a dádiva. Forma e razão da troca nas sociedades arcaicas.

In: Sociologia e Antropologia. São Paulo: Cosac \& Naify, 2003, p. 183-314.

MELO, H. P.; CONSIDERA, C. M.; DI SABBATO, A. Os afazeres domésticos contam. Economia e sociedade, Campinas-SP, v. 16, n. 3, p. 435-454, dez. 2007.

MINAYO, M. C. S. (Org.). Pesquisa social: teoria, método e criatividade. Petrópolis, RJ: Vozes, 2010.

MONTICELLI, T. A. Diaristas, afeto e escolhas: ressignificações no trabalho doméstico remunerado. 2013. 170 f. Dissertação (Mestrado em Sociologia) - Programa de Pós-Graduação em Sociologia, Universidade Federal do Paraná, Curitiba.

MORI, N., et al. (Orgs.). Tensões e experiências: um retrato das trabalhadoras domésticas de Brasília e Salvador. Brasília: CFEMEA, MDG3 Fund., 2011.

MURILlO, A. L. O uso das biografias nas pesquisas antropológicas. Revista Perspectivas Sociais, Pelotas-RS, v. 2, n. 1, p. 2-10, mar. 2013.

PEIRANO, M. G. S. O Encontro Etnográfico e o Diálogo Teórico. In: Uma Antropologia no Plural: três experiências contemporâneas. Brasília: UnB, 1991. p. 131-146.

PINHEIRO, L. S., et al (Orgs.). Mulheres e Trabalho: breve análise do período 2004-2014. (Nota Técnica nº. 24). Brasília: IPEA, 2016. 
PINHO, O. S.; ARAÚJO, T. M. Associação entre sobrecarga doméstica e transtornos mentais comuns em mulheres. Revista Brasileira de Epidemiologia, São Paulo, v. 15, n. 3, p. 560-572, 2012.

PRISCO, T.; CARVALHO, C. S.; GOMES, M. M. Diaristas: “Novas Domésticas” em Tempos de Trabalho Precário? Serviço Social em Revista, Londrina-PR, v. 15, n. 2, p. 28-50, jan./jul. 2013.

QUEIROZ, E. P. A migração intrametropolitana no Distrito Federal e Entorno: o consequente fluxo pendular e o uso dos equipamentos urbanos de saúde e educação. In: ENCONTRO NACIONAL DE ESTUDOS POPULACIONAIS, 15, 2006, Caxambú-MG. Anais da ABEP. Caxambú-MG, 2006, p. 1-17.

RAMOS, F. H. A. Dor nas costas e o trabalho doméstico. 2003. 41 f. Trabalho de Conclusão de Curso (Especialização em Saúde do Trabalho) - Universidade Federal do Paraná, Curitiba.

SÁNCHEZ, C. A. Biografía etnográfica. In: BAZTÁN, A. A. Etnografía: metodología cualitativa en la investigación sociocultural. España: Marcombo, 1995. p. 209-220.

TAMANINI, M., et al. Saúde-doença na interação entre gênero e trabalho: um estudo das representações das empregadas domésticas. 1997. 179 f. Dissertação (Mestrado em Sociologia Política) - Programa de Pós-graduação em Sociologia Política, Universidade Federal de Santa Catarina, Florianópolis.

YOSHIKAI, L. M. O. Análise psicossocial da trabalhadora doméstica através das representações sociais do trabalho. 2009. 113 f. Dissertação (Mestrado em Psicologia) - Instituto de Psicologia, Universidade de São Paulo, São Paulo.

Recebido em: 13/07/2017

Aceito em: 26/11/2018 